\title{
Exhaled nitric oxide, susceptibility and new- onset asthma in the Children's Health Study
}

\author{
T.M. Bastain, T. Islam, K.T. Berhane, R.S. McConnell, E.B. Rappaport, M.T. Salam, \\ W.S. Linn, E.L. Avol, Y. Zhang and F.D. Gilliland
}

ABSTRACT: A substantial body of evidence suggests an aetiological role of inflammation, and oxidative and nitrosative stress in asthma pathogenesis. Exhaled nitric oxide fraction $(\mathrm{FeNO})$ may provide a noninvasive marker of oxidative and nitrosative stress, and aspects of airway inflammation. We examined whether children with elevated FeNO are at increased risk for newonset asthma.

We prospectively followed 2,206 asthma-free children (age 7-10 yrs) who participated in the Children's Health Study. We measured FeNO and followed these children for 3 yrs to ascertain incident asthma cases. Cox proportional hazard models were fitted to examine the association between $F \mathrm{eNO}$ and new-onset asthma.

We found that $F$ eNO was associated with increased risk of new-onset asthma. Children in the highest $F$ eNO quartile had more than a two-fold increased risk of new-onset asthma compared to those with the lowest quartile (hazard ratio $2.1,95 \% \mathrm{Cl} 1.3-3.5$ ). This effect did not vary with the child's history of respiratory allergic symptoms. However, the effect of elevated FeNO on newonset asthma was most apparent among those without a parental history of asthma.

Our results indicate that children with elevated $\mathrm{FeNO}$ are at increased risk for new-onset asthma, especially if they have no parental history of asthma.

KEYWORDS: Airway inflammation, exhaled nitric oxide, incident asthma

A sthma is the most common childhood chronic disease and studies have documented its rise in prevalence over the past several decades [1]. Although the aetiology of asthma has been extensively studied, the pathogenesis and the factors causing the rapid rise in prevalence have yet to be firmly established. To reduce the burden from asthma, more research that focuses on asthma pathogenesis is needed. The current understanding of the pathogenesis of asthma suggests that oxidative and nitrosative stress, and dysregulated inflammatory responses play a role in asthma aetiology [2,3]. Exhaled nitric oxide fraction $(\mathrm{FeNO})$ provides a noninvasive marker of oxidative and nitrosative stress, and aspects of airway inflammation that may have a role in childhood asthma and allergic airway disease pathogenesis $[4,5]$.

The potential usefulness of FeNO in studies of asthma aetiology is illustrated by a recent Swedish population-based study of healthy adults without respiratory symptoms that found that elevated FeNO predicted the development of wheeze [6].
The Children's Health Study (CHS), a longitudinal population-based study of respiratory health among school-age children in 13 communities in Southern California, USA, provided an opportunity to investigate whether children with elevated FeNO are at increased risk of new-onset asthma. We also hypothesised that the elevated risk of new-onset asthma associated with FeNO differs with the child's allergic status and parental history of asthma. We examined the association of newonset asthma with FeNO using data collected annually in 2004-2007 from a cohort of 2,206 children whose parents did not report a physician diagnosis of asthma at study entry.

\section{METHODS \\ Study subjects}

Participants were from a CHS cohort enrolled during 2002-2003 when they were in kindergarten or first grade (average 5-6 yrs old). Informed consent from a parent or guardian and assent from each child were obtained before FeNO testing. The University of Southern California's Institutional Review Board (Los Angeles, CA, USA) approved

\section{AFFILIATIONS}

Dept of Preventive Medicine, Keck School of Medicine, University of Southern California, Los Angeles, CA, USA.

CORRESPONDENCE

F. Gilliland

Dept of Preventive Medicine Keck School of Medicine

1540 Alcazar Street

CHP 236

Los Angeles

CA 90033

USA

E-mail: gillilan@usc.edu

Received:

Feb 072010

Accepted after revision:

June 192010

First published online:

July 152010 
the protocol. Parents completed an annual self-administered questionnaire that included sociodemographic and child health characteristics, and a brief exposure history, including exposure to second-hand tobacco smoke and in utero exposure to maternal smoking. During 2004-2005, parental consent was obtained and FeNO testing was performed on 2,585 (82\%) subjects out of 3,146 eligible cohort members. We further excluded children whose parents reported a physician diagnosis of asthma during the school year of FeNO testing $(n=62)$, children who were lost to follow-up during the year after FeNO testing $(n=241)$ and children whose breath samples were invalidated due to storage or technical problems with the analyser $(n=76)$, resulting in 2,206 subjects.

\section{New-onset asthma definition}

An incident asthma case was defined as a child with no prior parental report of a physician diagnosis of asthma at FeNO testing whose parent reported a physician diagnosis of asthma in an annual follow-up questionnaire during the 3-yr followup period.

\section{Sociodemographic and medical history information}

Race/ethnicity was defined as non-Hispanic white, Hispanic, African-American, Asian/Hawaiian/Pacific Islander or mixed/ other ethnicities, based on parental report. Education was defined as the highest level of education attainment of the parent or guardian who completed the questionnaire. Annual household income was used to assess the role of socioeconomic status. We dichotomised self-reported health insurance coverage to assess the role of access to health care.

At study entry, selected aspects of the child's and parents' medical histories were collected, and in each successive school year, an update questionnaire inquiring about the child's intervening year of health was completed by parents and returned to study staff. Child's history of respiratory allergy included any hay fever or allergic rhinitis. Child's history of ever wheezing and wheezing in the past 12 months were defined as "yes" or "no". Parental history of asthma was defined as an asthma diagnosis in either biological parent. During annual school visits, subjects' height and weight were measured using standardised protocols.

\section{FeNO collection and analysis}

Details of breath collection and FeNO analysis used in this study were reported previously $[7,8]$. In brief, offline breath collection was performed in the morning at schools to avoid traffic-related peaks of ambient nitric oxide and possible effects of recent eating, according to American Thoracic Society recommendations $[9,10]$. Each $\mathrm{CHS}$ community was visited at least twice in different seasons, in order to minimise confounding of location and season effects. Health status at testing was evaluated by questionnaire; subjects with symptoms of acute respiratory infection within the past 3 days were excluded or rescheduled. Exhaled breath samples for offline testing were obtained using Bag Collection and Sampling Kits and 1.5-L aluminised Mylar bags (Sievers Division, GE Analytical Instruments, Boulder, CO, USA) by the deadspace-discard method at $100 \mathrm{~mL} \cdot \mathrm{s}^{-1}$ expiratory flow, stored in temperaturecontrolled coolers, and transported to and analysed at a central laboratory (Sievers Model 280i chemiluminescent NO analyser).
Indoor air samples were also collected to estimate subjects' ambient nitric oxide exposure at testing. Lag times between collection and analysis ranged from 2 to $26 \mathrm{~h}$. When this study began, offline collection was the most feasible method of collection for large field studies. Excellent agreement has been demonstrated between offline and online measurements in laboratory-based studies, using a variety of techniques [11-13]. In this study, offline FeNO values were converted to online FeNO values for all children, as would be measured at $50 \mathrm{~mL} \cdot \mathrm{s}^{-1}$ expiratory flow [10], using a prediction model (model adjusted $\mathrm{r}^{2}=0.94$ ) determined in a later substudy of 362 children with concurrent online and offline FeNO measurements [7]. The substudy included one or two testing days at each of 15 schools in eight communities in order to cover most of the geographic and seasonal range. Online measurements were performed at $50 \mathrm{~mL} \cdot \mathrm{s}^{-1}$ expiratory flow using EcoMedics CLD-88-SP analysers, with DeNOx accessories to provide nitric oxide-free inhaled air (EcoPhysics Inc., Ann Arbor, MI, USA), according to the manufacturer's instructions based on professional societies' recommendations [4, 9-10]. The prediction model included adjustment for ambient nitric oxide concentration, and lag time between collection and analysis. We used predicted online FeNO (hereafter, FeNO) in subsequent analyses.

\section{Statistical methods}

In order to investigate the relationship of FeNO with new-onset asthma, we calculated incidence rates and conducted descriptive analyses, and explored a series of multivariate modelling approaches in order to account for potential confounders and heterogeneity of effects within subgroups of children. Crude incidence rates for new-onset asthma were calculated by dividing the number of cases by the total person-years at risk. For children who developed new-onset asthma, follow-up was considered complete at the time of reported diagnosis. Incidence rates were calculated for age-specific quartiles of FeNO. We have previously shown that FeNO varies with age [8]. Therefore, age-specific FeNO quartiles were computed for each of three age strata (defined as $<8,8-9$ and $>9$ yrs) for analyses (see table S1 in the online supplementary material).

To further investigate the association between FeNO and newonset asthma, we fitted Cox proportional hazards models with sex- and age-specific baseline hazards (with age defined as integer age at FeNO testing). All models were adjusted for community of residence and race/ethnicity to account for the study design, and we assessed potential confounders identified a priori, including parental education, annual family income, health insurance, parental history of asthma, body mass index (BMI), household pets or pests, humidifier use, average outdoor air pollution levels on the day of the FeNO measurement (nitrogen dioxide, ozone, and particles with a $50 \%$ cut-off aerodynamic diameter of 2.5 and $10 \mu \mathrm{m}$ ), lifetime second-hand smoke (SHS) exposure and in utero exposure to maternal smoking. Covariates were considered confounders if the hazard ratio changed by $10 \%$ after addition to the base model. The final model was additionally adjusted for lifetime history of wheezing. Heterogeneity of associations among subgroups was assessed by fitting models with appropriate interaction terms, and statistical significance was tested by partial likelihood ratio tests [14]. Stratified analyses were 
performed in the presence of significant interaction ( $\mathrm{p}$-value $<0.05$ ). The nature of the nonlinearity in FeNO effects was explored using splines, piecewise cubic polynomials that are joined smoothly at a number of breakpoints known as knots [15].

Sensitivity analyses were conducted by limiting the asthma case definition to those 1) reporting a diagnosis $>1 \mathrm{yr}$ after FeNO testing, 2) without a history of respiratory allergy and 3 ) reporting use of inhaled medication in the diagnosis year follow-up questionnaire. To explore the role of wheezing prior to the onset of asthma, we restricted the analysis to children without a history of ever wheezing and wheezing 12 months prior to FeNO testing.

All analyses were conducted using SAS software (SAS Institute, Cary, NC, USA) version 9.1. All hypothesis testing was conducted assuming a 0.05 significance level and a twosided alternative hypothesis.

\section{RESULTS}

\section{Study population and cohort follow-up}

Descriptive analyses are presented in table 1. There were approximately equal numbers of males and females, and sex was not associated with new-onset asthma. Nearly $50 \%$ of children were 8-9 yrs of age at the initial FeNO measurement. The population was ethnically diverse: $55 \%$ of the participants were Hispanic white. This was largely a middle-class population: the majority of children lived in households earning more than US\$50,000 per year, had health insurance and had parents with at least some university education. None of these characteristics was associated with new-onset asthma.

We ascertained 129 cases of new-onset asthma over a 3-yr follow-up period (69 females and 60 males). The overall crude incidence rate was 22.2 per 1,000 person-yrs (see table S2 in the online supplementary material for rates by sex, ethnicity and other select characteristics). The overall mean and median follow-up times were 2.59 and 2.93 yrs, respectively, and $\sim 25 \%$ of the participants were lost prior to the end of followup. The proportion of possible follow-up time did not vary substantially by sex, ethnicity or FeNO quartile; however, there were small but significant differences in loss to follow-up rates with respect to parental education, family income and child's health insurance coverage (data not shown). Based on telephone interviews conducted in the CHS with the families of subjects who left the study schools, loss to follow-up was primarily due to family moves out of the school catchment area related to a change in employment [16].

\section{Selected health and exposure characteristics, and risk of new-onset asthma}

$50 \%$ of the participants reported having no history of respiratory allergy at study entry; the remaining 50\% were split evenly between past history of respiratory allergy (history of hay fever or allergic rhinitis but no current symptoms) and current respiratory allergy (symptoms within the previous 12 months) (table 1). Children with any history of respiratory allergy showed an increased risk of new-onset asthma relative to the never-allergy group. Any history of wheezing and wheezing in the 12 months prior to FeNO testing were present in $27 \%$ and $5 \%$ in the participants, respectively, and were associated with a nearly five-fold increased risk of new-onset
TABLE 1 Subject characteristics and associations with new-onset asthma

Subject characteristics

Subjects $^{\#}$ n (\%) $\quad$ HR $^{*}(95 \% \mathrm{Cl})$
Total subjects

Females

Age at FeNO testing

$<8$ yrs

$8-9$ yrs

$>9 \mathrm{yrs}$

Race/ethnicity

Non-Hispanic White

Hispanic

African-American

Asian/Hawaiian/Pacific Islander

Other

Allergic status at study entry

Never

Former hayfever or allergic rhinitis

Current hayfever or allergic rhinitis

History of wheeze

Never

Lifetime wheeze

No wheeze 12 months prior to study entry

Wheeze 12 months prior to study entry

Any family history of asthma

Exposure to SHS

In utero exposure to maternal smoking

Annual household income US\$

$<15000$

15000-49999

$\geqslant 50000$

No health insurance

Parent education level

$<12$ th grade

12th grade

Some university

University

BMI percentile category

Underweight i.e. $<5$ th percentile

Normal weight i.e. 5th to $<85$ th percentile

Overweight/obese i.e. $\geqslant 85$ th percentile
Some postgraduate
$2206(100)$

1155 (52)

$1.01(0.71-1.44)$

699 (32)

$0.77(0.48-1.25)$

$1064(48) \quad 0.74(0.48-1.16)$

$443(20) \quad 1$

788 (36) 1

$1212(55) \quad 0.92(0.60-1.41)$

36 (2) $\quad 1.82(0.62-5.31)$

$67(30 \quad 0.64(0.20-2.09)$

101 (5) $\quad 1.30(0.61-2.78)$

$1104(50)$

$543(250 \quad 1.65(1.05-2.60)$

557 (25) $\quad 2.38(1.57-3.60)$

$1598(73)$

$604(270 \quad 4.85(3.38-6.96)$

1983 (95) 1

$110(5) \quad 4.95(3.12-7.86)$

317 (16) $\quad 1.99(1.32-3.01)$

206 (11) $0.99(0.55-1.80)$

131 (6) $\quad 0.87(0.40-1.90)$

268 (14) $1.29(0.69-2.40)$

594 (32) $\quad 1.04(0.64-1.69)$

$1003(54)$

260 (13) $\quad 1.14(0.64-2.03)$

$425(21) \quad 0.92(0.43-1.99)$

368 (18) $\quad 0.73(0.35-1.53)$

754 (36) $\quad 1.04(0.58-1.87)$

284 (14) $0.86(0.43-1.74)$

$242(12) \quad 1$

$54(2) \quad 2.05(0.82-5.14)$

$1371(62)$

$781(35)$

$1.44(0.99-2.08)$
HR: hazard ratio; FeNO: exhaled nitric oxide fraction; SHS: second-hand smoke; BMI: body mass index. ${ }^{*}$ : numbers may not sum to 2,206 due to missing values; " : adjusted for race/ethnicity and community with baseline strata for age and sex (where appropriate)

asthma. $16 \%$ reported a parental history of asthma which was associated with a two-fold increased risk of new-onset asthma in the child.

$62 \%$ of study participants had normal BMI at baseline. Neither underweight $(<5$ th BMI percentile) nor overweight/obese $(\geqslant 85$ th percentile) was significantly associated with increased risk of new-onset asthma. Neither lifetime SHS exposure nor in utero exposure to maternal smoking was associated with risk of new-onset asthma. Prevalence of SHS exposure and in utero 


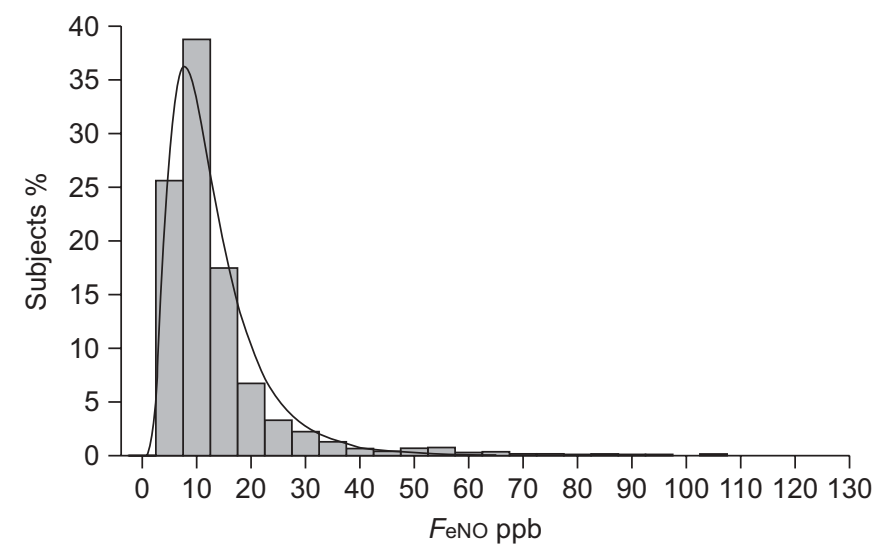

FIGURE 1. Distribution of exhaled nitric oxide fraction ( $F$ eNO) at baseline (mean \pm SD $13.6 \pm 12.0 \mathrm{ppb} ; \mathrm{n}=2,206)$.

exposure to maternal smoking in this population was lower than in previous CHS cohorts [17] (11\% and 6\%, respectively).

\section{Distribution of FeNO}

As we previously reported [8], FeNO followed an approximately log-normal distribution (mean $13.6 \mathrm{ppb}$; median $10.1 \mathrm{ppb}$; SD $12.0 \mathrm{ppb}$; range $2.3-132.4 \mathrm{ppb}$ ) (fig. 1). The median concentrations of FeNO (at baseline) among subjects who developed new-onset asthma was 10.9 ppb (range 3.2132.4 ppb) versus $10.1 \mathrm{ppb}$ (range 2.3-107.2 ppb) among subjects who did not develop asthma.

\section{FeNO and risk of new-onset asthma}

Elevated FeNO was associated with an increased risk of newonset asthma (table 2 and fig. 2). Children with FeNO in the highest quartile at the start of follow-up had more than a twofold increased risk of incident asthma compared to those with FeNO in the lowest quartile (HR 2.11, 95\% CI 1.26-3.51), after adjusting for race/ethnicity, community of residence and lifetime history of wheeze. We observed an increasing trend of asthma risk with increasing quartiles of FeNO (p-value for trend $<0.01$ ). The association of new-onset asthma with FeNO was not substantially affected by adjustment for parental education, family income, health insurance, family history of asthma, household pets or pests, humidifier use, BMI, daily average air pollution levels (on the day of FeNO measurement)
SHS exposure or in utero exposure to maternal smoking (data not shown).

To assess the role of past wheezing, we adjusted the risk estimates for wheezing history and conducted analyses among children without any history of wheezing. Adjustment for any history of wheezing changed the risk estimates by slightly more than $10 \%$. In sensitivity analyses restricting the cohort to children without a history of wheezing $(n=1,602)$ or without wheezing in the 12 months prior to FeNO measurement $(n=2,096)$, we found a similar increased risk of new-onset asthma for those with the highest quartile of FeNO (table 3).

To assess the effect of asthma case definition, we conducted analyses restricting cases to those with recent inhaled medication use. We found that the estimates for the effects of FeNO on new-onset asthma were larger (over four-fold risk comparing the highest to the lowest quartile of FeNO; table 4 and online supplementary table S3). To investigate the contribution of delayed asthma diagnosis, we restricted the analysis to followup starting in the second year and found that eliminating the first year of follow-up did not substantially alter the relative risk estimates for FeNO (table 4).

\section{FeNO and new-onset asthma by allergy status and parental history of asthma}

In contrast to our hypothesis, we did not find evidence that the effect of FeNO on new-onset asthma depended on respiratory allergy status (table 5). The pattern of increasing risk of newonset asthma with increasing FeNO was observed in children with and without a reported history of respiratory allergy.

The effect of FeNO on new-onset asthma differed among children with and without a parental history of asthma (table 6 and online supplementary fig. S1; p-value for interaction $<0.05$ ). The observed increase in risk of asthma development was most apparent among children without a parental history of asthma. Compared with children with the lowest FeNO quartile with no parental history of asthma, children in the highest FeNO quartile with no parental history of asthma had more than a three-fold increased risk of new-onset asthma (HR $3.18,95 \%$ CI 1.66-6.08). This pattern of increasing risk with increasing FeNO was observed among children with either maternal or paternal asthma (data not shown). Although parental history of asthma was directly associated with elevated risk of new-onset asthma, we observed little evidence for association of increasing $F$ eNO with increasing risk of

\section{TABLE 2 Association of exhaled nitric oxide fraction ( $F$ eNO) with new-onset asthma in the Children's Health Study}

\begin{tabular}{lccc} 
Age-specific quartiles of $\boldsymbol{F e N O}$ at baseline & New-onset asthma & No asthma & HR $^{\#}(\mathbf{9 5} \% \mathbf{C l )}$ \\
\hline All subjects $\mathbf{n}$ & 129 & 2077 & 1 \\
Quartile 1 & $24(19)$ & $528(25)$ & $1.53(0.89-2.63)$ \\
Quartile 2 & $30(23)$ & $521(25)$ & $1.68(0.97-2.90)$ \\
Quartile 3 & $30(23)$ & $523(25)$ & $2.11(1.26-3.51)$ \\
Quartile 4 & $45(35)$ & $505(24)$ & \\
\hline
\end{tabular}

Data are presented as $n(\%)$, unless otherwise stated. HR: hazard ratio. * : adjusted for race/ethnicity, lifetime wheeze and community with baseline strata for age and sex p-value for trend $<0.01$. 


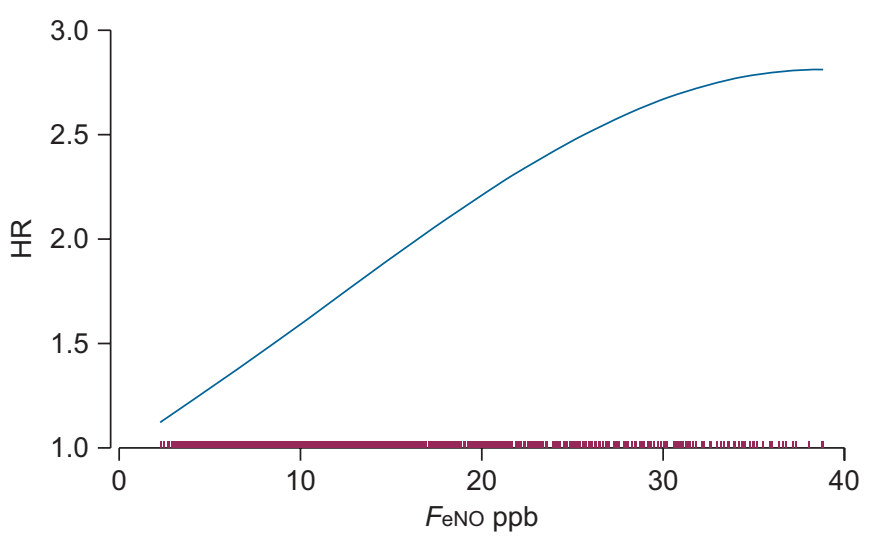

FIGURE 2. Hazard ratio (HR) function of the effect of exhaled nitric oxide fraction ( $\mathrm{FeNO}$ ) on new-onset asthma. The model was fit for subjects with FeNO $\leqslant 40 \mathrm{ppb}$ ( $\sim 95 \%$ of subjects) due to sparseness of data above $40 \mathrm{ppb}$

new-onset asthma in children with a parental history of asthma (although power was limited by sample size and number of cases in this group).

In further analyses, the association of FeNO with new-onset asthma did not differ in males or females, children of different ethnicity, those exposed to SHS, or those exposed in utero to maternal smoking (data not shown).

\section{DISCUSSION}

We found that children with higher FeNO had a substantial risk of incident asthma compared with children with low FeNO. The use of FeNO in asthma clinical practice has been extensively investigated [18]. While the role of FeNO in clinical practice remains unclear [19], a number of studies have supported the use of FeNO in monitoring adherence to medication [20], maintaining asthma control and predicting relapse [21, 22]. Especially in the presence of symptoms, elevated FeNO (e.g. $>35 \mathrm{ppb}$ in steroid-naïve patients) has been supportive of asthma diagnosis $[18,23]$. However, to our knowledge, this is the first investigation to demonstrate the predictive value of FeNO for identifying children at risk for developing asthma, thereby extending the utility of this marker beyond monitoring medication adherence, predicting asthma exacerbations or verifying a diagnosis.

A number of studies have identified a subgroup of individuals with elevated FeNO without asthma or asthma-related symptoms [24-27]. In a cross-sectional study of 13-14-yr-old schoolchildren, NORDVALL et al. [27] suggested that a small subset of participants with elevated levels of FeNO who reported no symptoms of asthma in the International Study of Asthma and Allergies in Childhood (ISAAC) questionnaire [28] may represent "early asthma". SIVAN et al. [29] compared the use of FeNO, spirometry and induced sputum eosinophil count in consecutive school-age children referred for evaluation of possible asthma. The sensitivity, specificity, and positive and negative predictive values for best cut-off points of $F$ eNO (19 ppb) were all $>80 \%$ and were very similar to those for sputum eosinophil count, suggesting that FeNO testing is about as effective as sputum induction in aiding the diagnosis of childhood asthma.

In a population-based prospective study of adults who were free of asthma or wheeze at study entry, OLIN et al. [6] found that baseline FeNO over the 90th percentile predicted newonset wheeze at 4-yr follow-up among adults. Because their study was underpowered to investigate new-onset asthma, the authors used new-onset wheeze as a surrogate and early marker of asthma. Regardless of wheeze history, elevated FeNO was predictive of new-onset asthma in our population of schoolchildren.

It is widely accepted that genetic factors account for a significant proportion of allergy and asthma occurrence [30, 31]. In this study, we found nearly a two-fold increased risk of newonset asthma in children with a parental history of asthma; however, the size of that risk did not vary significantly by quartiles of FeNO. The effect of elevated FeNO on new-onset asthma was more marked among children without a parental history of asthma. We previously reported that $23 \%$ of the parent cohort indicated a parental history of asthma at cohort establishment [32] (2 yrs before FeNO measurement). The prevalence of parental asthma in the current study was $16 \%$, probably due to the exclusion of prevalent asthma cases and cases diagnosed in the 2 yrs before FeNO measurement. Moreover, the proportion of cases with a parental history of

TABLE 3 Exhaled nitric oxide fraction ( $F$ eNO) and risk of new-onset asthma, restricted to children without lifetime wheezing and without wheezing in the 12 months prior to study entry

\section{Subjects $\mathbf{n}$ \\ Quartile 1 \\ Quartile 2 \\ Quartile 3 \\ Quartile 4 \\ ptrend}

1602
1
$2.09(0.89-4.95)$
$0.99(0.36-2.66)$
$2.42(1.00-5.86)$
0.19

\section{6}

1

$1.70(0.95-3.06)$

$1.41(0.76-2.63)$

$2.19(1.22-3.90)$

0.02

Data are presented as hazard ratio $(95 \% \mathrm{Cl})$, unless otherwise stated. ptrend: p-value for trend. ${ }^{*}$ : adjusted for race/ethnicity and community, and stratified by integer age and sex in children without a history of wheezing (48 cases and 1,554 noncases); ${ }^{\bullet}$ : adjusted for race/ethnicity and community, and stratified by integer age and sex in children without reported wheezing in the 12 months prior to study entry (105 cases and 1,991 noncases). 
TABLE 4 Exhaled nitric oxide fraction ( $F$ eNO) and risk of new-onset asthma: restricted case definitions

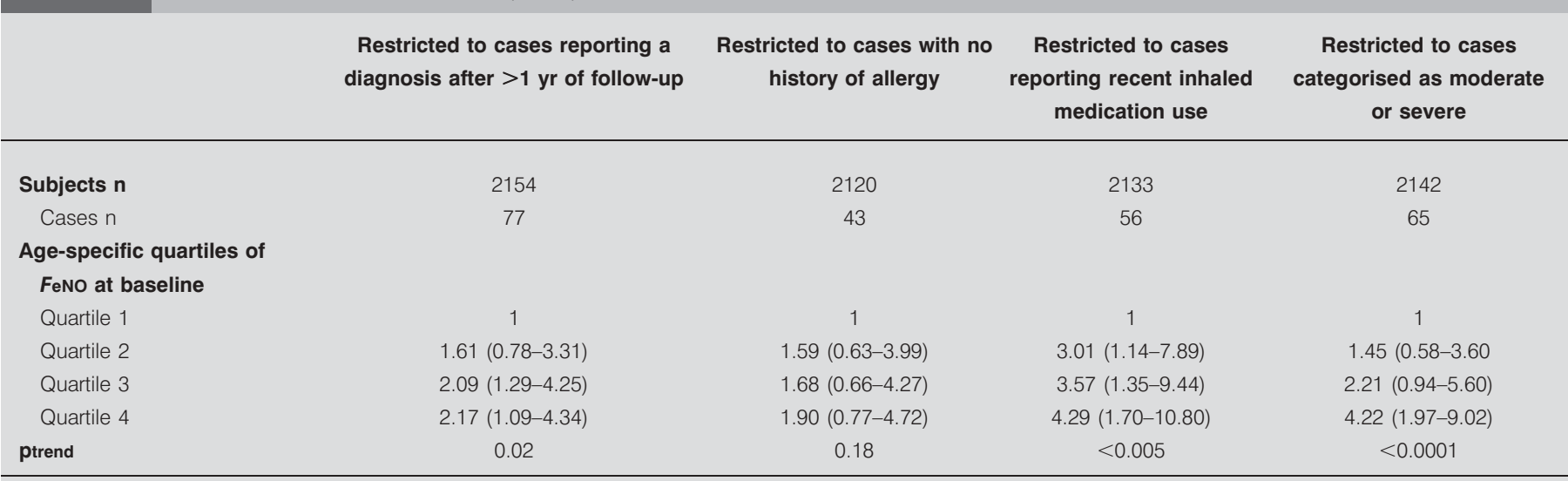

Data are presented as hazard ratio $(95 \% \mathrm{Cl})$, unless otherwise stated. Adjusted for race/ethnicity, community and lifetime wheeze, and stratified by integer age and sex. Recent inhaled medication use was defined as any rescue or controller medication in the previous 12 months, reported on the diagnosis year follow-up questionnaire. Moderate-to-severe asthma (65 cases) was defined as at least one attack of wheezing in the past 12 months or waking at night due to wheezing in the past 12 months (in the year of diagnosis on the follow-up questionnaire); 24 of these cases were defined as severe, which were classified as four or more wheeze attacks in the previous 12 months, one or more nights per week awakened with wheeze, or limited speech due to wheezing in the previous 12 months (in the diagnosis year on the follow-up questionnaire); due to the small numbers of severe cases, moderate and severe cases were combined in the analysis. ptrend: $\mathrm{p}$-value for trend.

asthma was quite similar by child's history of allergy; $29 \%$ of allergic and $24 \%$ of nonallergic cases had a parental history of asthma (data not shown).

While our analysis is based on small numbers, the absence of an increased risk in children with higher FeNO and a parental history of asthma (relative to children with lower FeNO and a parental history of asthma) may indicate that the new-onset asthma associated with FeNO is not mediated by the same pathways that account for the asthma in children with a parental history of asthma. Alternatively, our study may demonstrate that, beyond the age of 5-8 yrs, the impact of parental history on the development of asthma may be reduced.
Elevated inflammation and oxidative/nitrosative stress could also arise from exposure and/or susceptibility to environmental stressors, such as SHS or ambient air pollution. We have previously reported that the effects of air pollution on asthma risk may differ in children with and without a parental history of asthma. In a CHS cohort recruited in the 1990s, we showed that children who exercised heavily in high-ozone environments were at increased risk of new-onset asthma especially in the absence of a parental history of asthma [33]. We also demonstrated that traffic-related pollution was associated with a two-fold increased risk of lifetime asthma in children without a parental history of asthma [32]. Taken together, our results and previous findings support an

TABLE 5 Association of exhaled nitric oxide fraction (FeNO) with new-onset asthma by respiratory allergy status

Age-specific quartiles of FeNO at baseline

\section{History of respiratory allergy}

\begin{tabular}{|c|c|c|c|c|c|}
\hline \multicolumn{3}{|c|}{ Never } & \multicolumn{3}{|c|}{ Current or former } \\
\hline $\begin{array}{l}\text { New-onset } \\
\text { asthma }\end{array}$ & No asthma & $\mathrm{HR}^{\#}(95 \% \mathrm{Cl})$ & $\begin{array}{l}\text { New-onset } \\
\text { asthma }\end{array}$ & No asthma & $\mathrm{HR}^{\#}(95 \% \mathrm{Cl})$ \\
\hline
\end{tabular}

$\begin{array}{lcccccc}\text { Quartile 1 } & 8 & 259 & 1 & 16 & 269 & 1.20(0.51-2.84) \\ \text { Quartile 2 } & 11 & 310 & 1.30(0.52-3.23) & 19 & 211 & 2.10(0.91-4.85) \\ \text { Quartile 3 } & 11 & 280 & 1.67(0.66-4.20) & 19 & 243 & 2.01(0.87-4.63) \\ \text { Quartile 4 } & 13 & 212 & 2.21(0.90-5.38) & 32 & 2.44(1.10-5.39) \\ \text { ptrend } & & & <0.05^{\circ} & & & <0.05^{\circ} \\ \text { pinteraction } & & & & 0.89^{+} & \end{array}$

Data are presented as n, unless otherwise stated. HR: hazard ratio; ptrend: p-value for trend; pinteraction: p-value for interaction. *: adjusted for race/ethnicity, lifetime wheeze and community with baseline strata for age and sex; ${ }^{\bullet}$ : trend tests conducted in stratified models; ${ }^{+}$: based on the Chi-squared statistic using the likelihood ratio test to compare a model with base terms to a model also containing the multiplicative interaction term. 


\section{TABLE 6 Association of exhaled nitric oxide ( $\mathrm{FeNO}$ ) with new-onset asthma by parental history of asthma}

\begin{tabular}{l}
$\begin{array}{l}\text { Age-specific quartiles of } \\
\text { FeNO at baseline }\end{array}$ \\
\cline { 2 - 5 } \\
\cline { 2 - 5 }
\end{tabular}

aetiological role for inflammation in asthma pathogenesis. Further research is needed to determine whether pro-inflammatory environmental stressors may help to explain why we see the largest effects of $F$ eNO in children without a parental history of asthma.

A body of evidence indicates that FeNO is elevated in allergic airway disease $[4,5]$ and studies have shown FeNO to be elevated in healthy atopic children [34]. We did not find evidence that the effect of FeNO depended on the child's allergy status. Children with and without a history of respiratory allergy showed similar patterns of increasing risk of new-onset asthma by increasing quartiles of FeNO.

While our results suggest that the relationship of FeNO with new-onset asthma may be independent of the allergic pathway, it is important to note that we used parent-report of hayfever or allergic rhinitis as a measure of children's respiratory allergy status, which may result in measurement error of true atopic status. However, measurement error is not likely to explain our entire findings as significant residual confounding by atopic status would likely occur only if the true associations between atopy and FeNO and between atopy and new onset asthma are both very strong (e.g. relative risks of 10.0) [35]. The strong relationships of self-reported measures of allergy with FeNO and asthma provide evidence that measurement error of atopic status is not likely to explain our findings.

The incidence rate of physician-diagnosed asthma in the present study (22.2 per 1,000 person-yrs) was higher than rates reported in earlier periods [36]. However, in recent decades, rates are more comparable, likely reflecting the increasing occurrence of childhood asthma $[37,38]$. The incidence rate in the present study is consistent with earlier CHS cohorts of approximately the same age (17.8 per 1,000 person-yrs) [17]. By restricting our case definition to children without any history of wheezing, the incidence rate remained substantial (11.1 per 1,000 person-yrs).
A recognised limitation of our study is our reliance on selfreport of physician-diagnosed asthma for defining eligibility and for case ascertainment. However, physician diagnosis of asthma has been widely accepted as a valid method of classifying asthma status in large epidemiological studies $[39,40]$. In a subset of a previous CHS cohort, we independently verified self-reported physician-diagnosed asthma through a review of medical records and found that $>95 \%$ of the children with a self-reported diagnosis had either a definite or probable asthma diagnosis noted on the medical record [41]

Another potential influence on asthma diagnosis is differential access to care and differences in medical practice. We found that adjustment for various indicators of socioeconomic status did not change our results, and we found that by restricting our analysis to cases using recent inhaled medication or by restricting to cases categorised as moderate or severe resulted in stronger risk estimates at each FeNO quartile; therefore, any bias that might arise from differences in medical practice is likely to attenuate the risk estimate toward the null. Children who reported use of inhaled medication after diagnosis could represent children with more bronchial inflammation before asthma onset and more severe asthma at diagnosis.

While this cohort was initially established when the participants were young (aged 5-6 yrs on average), we cannot definitively state that a new asthma diagnosis represents a true incident case. Misclassification of asthma status at cohort entry is not likely to explain our findings, as excluding cases reporting a diagnosis in the first year of follow-up did not substantially alter the relative risk estimates. To further limit the inclusion of possible undiagnosed asthma, we restricted our analysis to children without a history of wheeze or without wheeze in the twelve months prior to FeNO measurement. The results remained consistent with the highest risk of new-onset asthma occurring in children with the highest quartile of FeNO.

\section{Conclusions}

Our results suggest that $\mathrm{FeNO}$ is a marker of risk for the development of asthma especially among children without a 
parental history of asthma. FeNO may be valuable in developing primary prevention strategies.

\section{SUPPORT STATEMENT}

This work was supported by the Southern California Environmental Health Sciences Center (grant number 5P30ES007048) funded by the National Institute of Environmental Health Sciences, the Children's Environmental Health Center (grant numbers 5P01ES009581, R826708-01 and RD831861-01) funded by the National Institute of Environmental Health Sciences and the Environmental Protection Agency, the National Institute of Environmental Health Sciences (grant number 5P01ES011627), the National Heart, Lung and Blood Institute (grant numbers 5R01HL061768 and 5R01HL076647) and the Hastings Foundation.

\section{STATEMENT OF INTEREST}

None declared.

\section{ACKNOWLEDGEMENTS}

We are indebted to the school principals, teachers, students and parents in each of the 13 study communities for their cooperation and especially to the members of the health testing field team for their efforts.

\section{REFERENCES}

1 Eder W, Ege MJ, von Mutius E. The asthma epidemic. N Engl J Med 2006; 355: 2226-2235.

2 Steerenberg PA, Janssen NA, De Meer G, et al. Relationship between exhaled NO, respiratory symptoms, lung function, bronchial hyperresponsiveness, and blood eosinophilia in school children. Thorax 2003; 583242-583245.

3 Djukanovic R, Lai CK, Wilson JW, et al. Bronchial mucosal manifestations of atopy: a comparison of markers of inflammation between atopic asthmatics, atopic nonasthmatics and healthy controls. Eur Respir J 1992; 5: 538-544.

4 Baraldi E, de Jongste JC. Measurement of exhaled nitric oxide in children, 2001. Eur Respir J 2002; 20: 223-237.

5 Kharitonov SA, Barnes PJ. Biomarkers of some pulmonary diseases in exhaled breath. Biomarkers 2002; 7: 1-32.

6 Olin AC, Rosengren A, Thelle DS, et al. Increased fraction of exhaled nitric oxide predicts new-onset wheeze in a general population. Am J Respir Crit Care Med 2010; 181: 324-327.

7 Linn WS, Berhane KT, Rappaport EB, et al. Relationships of online exhaled, offline exhaled, and ambient nitric oxide in an epidemiologic survey of schoolchildren. J Expo Sci Environ Epidemiol 2008; 19: 674-681.

8 Linn WS, Rappaport EB, Berhane KT, et al. Exhaled nitric oxide in a population-based study of southern California schoolchildren. Respir Res 2009; 10: 28.

9 Recommendations for standardized procedures for the on-line and off-line measurement of exhaled lower respiratory nitric oxide and nasal nitric oxide in adults and children - 1999. This official statement of the American Thoracic Society was adopted by the ATS Board of Directors, July 1999. Am J Respir Crit Care Med 1999; 160: 2104-2117.

10 ATS/ERS recommendations for standardized procedures for the online and offline measurement of exhaled lower respiratory nitric oxide and nasal nitric oxide, 2005. Am J Respir Crit Care Med 2005; 171: 912-930.

11 Barreto M, Villa MP, Martella S, et al. Off-line exhaled nitric oxide measurements in children. Pediatr Pulmonol 2001; 32: 159-167.

12 Deykin A, Massaro AF, Drazen JM, et al. Exhaled nitric oxide as a diagnostic test for asthma: online versus offline techniques and effect of flow rate. Am J Respir Crit Care Med 2002; 165: 1597-1601.
13 Linn WS, Avila M, Gong H Jr. Exhaled nitric oxide: sources of error in offline measurement. Arch Environ Health 2004; 59: 385-391.

14 Cox DR. Regression models and life tables. J Royal Stat Soc B 1972; 34: 187-202.

15 Hastie TJ, Tibshirani RJ. Generalized Additive Models. New York, Chapman and Hall, 1990.

16 Islam T, Gauderman WJ, Berhane K, et al. Relationship between air pollution, lung function and asthma in adolescents. Thorax 2007; 62: 957-963.

17 Gilliland FD, Islam T, Berhane $\mathrm{K}$, et al. Regular smoking and asthma incidence in adolescents. Am J Respir Crit Care Med 2006; 174: 1094-1100.

18 Lim KG, Mottram C. The use of fraction of exhaled nitric oxide in pulmonary practice. Chest 2008; 133: 1232-1242.

19 Petsky HL, Cates CJ, Li AM, et al. Tailored interventions based on exhaled nitric oxide versus clinical symptoms for asthma in children and adults. Cochrane Database Syst Rev 2008; 2: CD006340.

20 Jones SL, Kittelson J, Cowan JO, et al. The predictive value of exhaled nitric oxide measurements in assessing changes in asthma control. Am J Respir Crit Care Med 2001; 1645: 738-743.

21 Fritsch M, Uxa S, Horak F Jr, et al. Exhaled nitric oxide in the management of childhood asthma: a prospective 6-months study. Pediatr Pulmonol 2006; 419: 855-862.

22 Pijnenburg MW, Hofhuis W, Hop WC, et al. Exhaled nitric oxide predicts asthma relapse in children with clinical asthma remission. Thorax 2005; 603: 215-218.

23 Smith $\mathrm{AD}$, Cowan JO, Filsell S, et al. Diagnosing asthma comparisons between exhaled nitric oxide measurements and conventional tests. Am J Respir Crit Care Med 2004; 169: 473-478.

24 Ludviksdottir D, Janson C, Hogman M, et al. Exhaled nitric oxide and its relationship to airway responsiveness and atopy in asthma. BHR Study Group. Respir Med 1999; 93: 552-556.

25 Henriksen AH, Lingaas-Holmen T, Sue-Chu M, et al. Combined use of exhaled nitric oxide and airway hyperresponsiveness in characterizing asthma in a large population survey. Eur Respir J 2000; 15: 849-855.

26 Olin AC, Rosengren A, Thelle DS, et al. Height, age, and atopy are associated with fraction of exhaled nitric oxide in a large adult general population sample. Chest 2006; 130: 1319-1325.

27 Nordvall SL, Janson C, Kalm-Stephens P, et al. Exhaled nitric oxide in a population-based study of asthma and allergy in schoolchildren. Allergy 2005; 60: 469-475.

28 Strachan D, Sibbald B, Weiland S, et al. Worldwide variations in prevalence of symptoms of allergic rhinoconjunctivitis in children: the International Study of Asthma and Allergies in Childhood (ISAAC). Pediatr Allergy Immunol 1997; 8: 161-176.

29 Sivan Y, Gadish T, Fireman E, et al. The use of exhaled nitric oxide in the diagnosis of asthma in school children. J Pediatr 2009; 155: 211-216.

30 Moffatt MF, Cookson WO. Gene identification in asthma and allergy. Int Arch Allergy Immunol 1998; 116: 247-252.

31 Liu T, Valdez R, Yoon PW, et al. The association between family history of asthma and the prevalence of asthma among US adults: National Health and Nutrition Examination Survey, 1999-2004. Genet Med 2009; 11: 323-328.

32 McConnell R, Berhane K, Yao L, et al. Traffic, susceptibility, and childhood asthma. Environ Health Perspect 2006; 114: 766-772.

33 McConnell R, Berhane K, Gilliland F, et al. Asthma in exercising children exposed to ozone: a cohort study. Lancet 2002; 359: 386-391.

34 Franklin PJ, Taplin R, Stick SM. A community study of exhaled nitric oxide in healthy children. Am J Respir Crit Care Med 1999; 159: 69-73.

35 Kelsey JL, Thompson WD, Evans AS. Methods in Observational Epidemiology. New York, Oxford University Press, 1986. 
36 Dodge RR, Burrows B. The prevalence and incidence of asthma and asthma-like symptoms in a general population sample. Am Rev Respir Dis 1980; 122: 567-575.

37 Basagana X, Sunyer J, Zock JP, et al. Incidence of asthma and its determinants among adults in Spain. Am J Respir Crit Care Med 2001; 164: 1133-1137.

38 Strachan DP, Butland BK, Anderson HR. Incidence and prognosis of asthma and wheezing illness from early childhood to age 33 in a national British cohort. BMJ 1996; 312: 1195-1199.
39 Worldwide variation in prevalence of symptoms of asthma, allergic rhinoconjunctivitis, and atopic eczema: ISAAC. The International Study of Asthma and Allergies in Childhood (ISAAC) Steering Committee. Lancet 1998; 351: 1225-1232.

40 Burr ML. Diagnosing asthma by questionnaire in epidemiological surveys. Clin Exp Allergy 1992; 22: 509-510.

41 Salam MT, Li YF, Langholz B, et al. Early-life environmental risk factors for asthma: findings from the Children's Health Study. Environ Health Perspect 2004; 112: 760-765. 